\title{
Erratum to: Alkylation of Aromatic Compounds in the Presence of Catalysts Based on Mesoporous Phenol-Formaldehyde Polymers
}

M. P. Boronoev ${ }^{a}$, Ma Guojun ${ }^{a}$, M. Yu. Talanova ${ }^{a}$, and E. A. Karakhanov ${ }^{a}$, *

${ }^{a}$ Faculty of Chemistry, Moscow State University, Moscow, Russia *e-mail: kar@petrol.chem.msu.ru

Submitted September 29, 2020; accepted for publication September 29, 2020

DOI: $10.1134 /$ S0965544120110079

The surname of the second author should read Ma Guojun

The original article can be found online at https://doi.org/10.1134/S0965544118050043 